\title{
Planning Practice and Research
}

\section{Is it just a guessing game? The application of Crime Prevention through Environmental Design (CPTED) to predict future burglary

\author{
--Manuscript Draft--
}

\begin{tabular}{|l|l|}
\hline Full Title: & $\begin{array}{l}\text { Is it just a guessing game? The application of Crime Prevention through Environmental } \\
\text { Design (CPTED) to predict future burglary }\end{array}$ \\
\hline Manuscript Number: & CPPR-2017-0054R1 \\
\hline Article Type: & Original Article \\
\hline Keywords: & $\begin{array}{l}\text { Crime Prevention through Environmental Design (CPTED); burglary; police; } \\
\text { residential housing; planning }\end{array}$ \\
\hline Abstract: & $\begin{array}{l}\text { Crime Prevention through Environmental Design (CPTED) aims to reduce crime } \\
\text { through the design of the built environment. Designing out Crime Officers (DOCOs) are } \\
\text { responsible for the delivery of CPTED by assessing planning applications, identifying } \\
\text { criminogenic design features and offering remedial advice. Twenty-eight experienced } \\
\text { DOCOs from across England and Wales assessed the site plan for one residential } \\
\text { development (which had been built a decade earlier) and identified crime risk locations. } \\
\text { Predictions of likely locations were compared with four years' police recorded crime } \\
\text { data. DOCOs are, to varying extents, able to identify locations which experienced } \\
\text { higher levels of crime and disorder. However, they varied widely in the number of } \\
\text { locations in which they anticipated burglary would occur. }\end{array}$ \\
\hline
\end{tabular}


Click here to access/download;Figure;FIGURE 1.tif $\underline{\underline{\underline{ }}}$

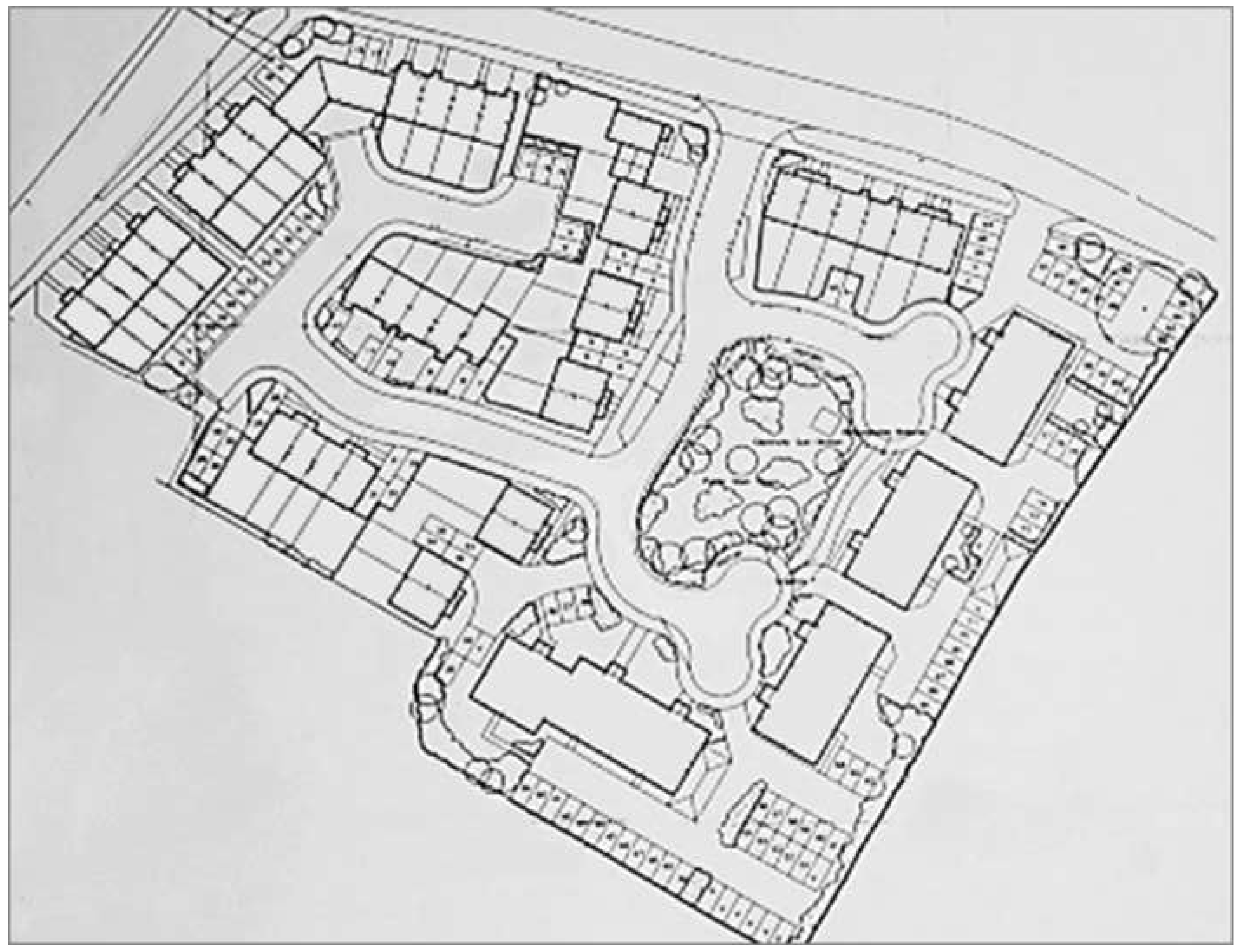




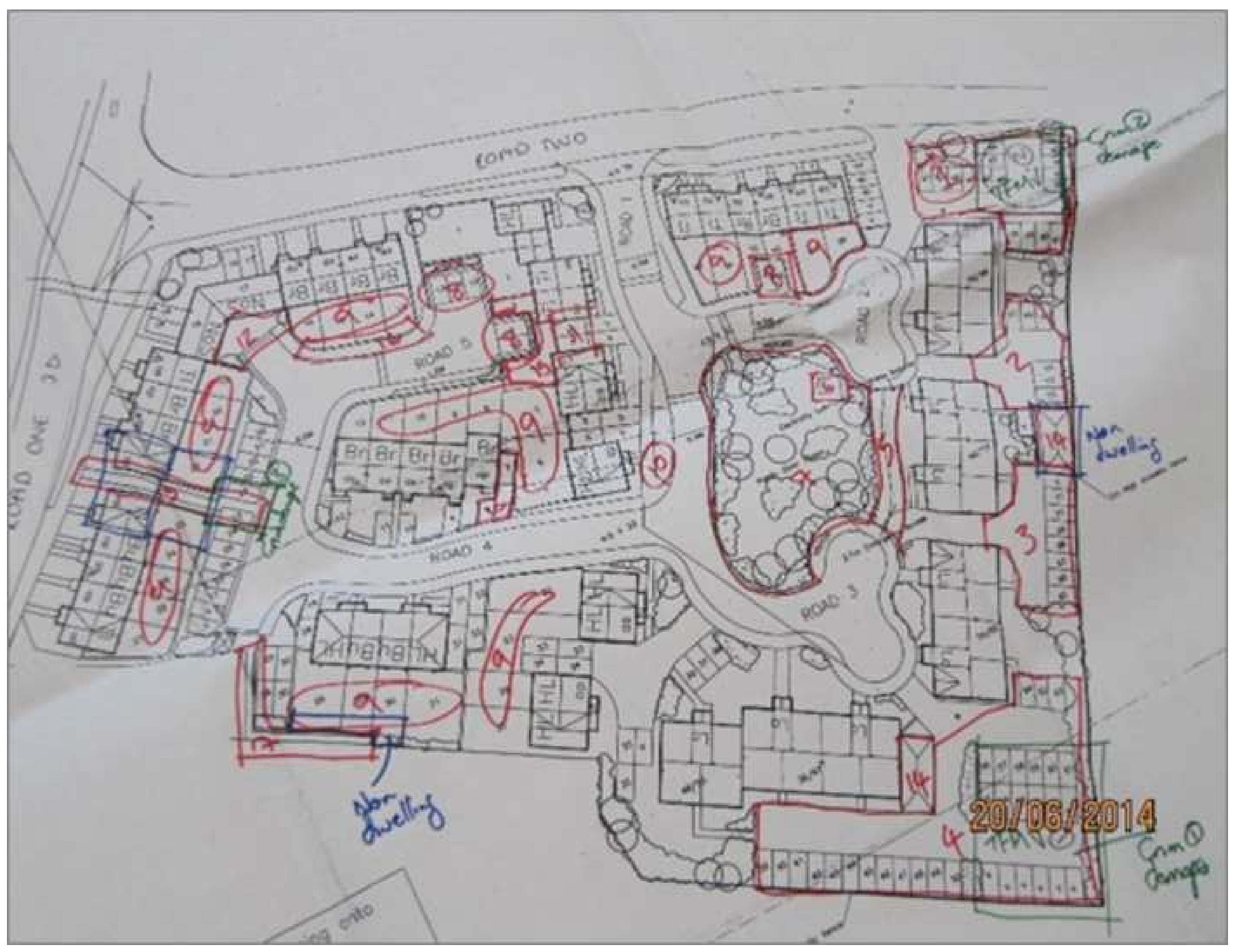




\section{7}

6

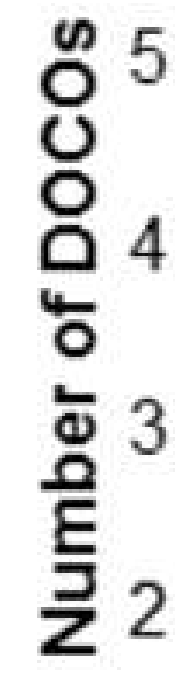

1

0
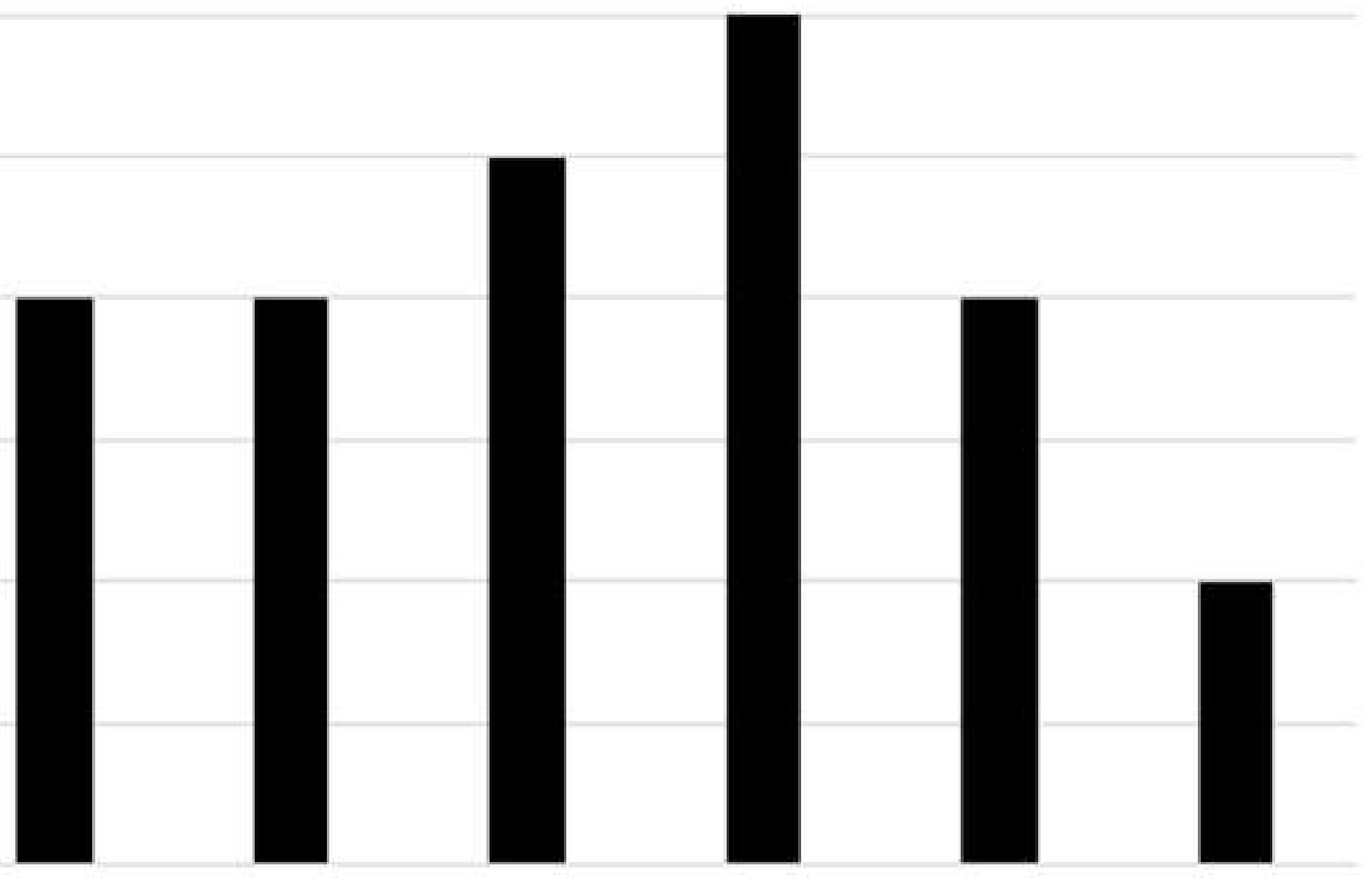

0 to 4

5 to 9

10 to 14

15 to 19

1920

0 to 24

25 to 2930 to 35 Number of locations identified at risk of burglary 


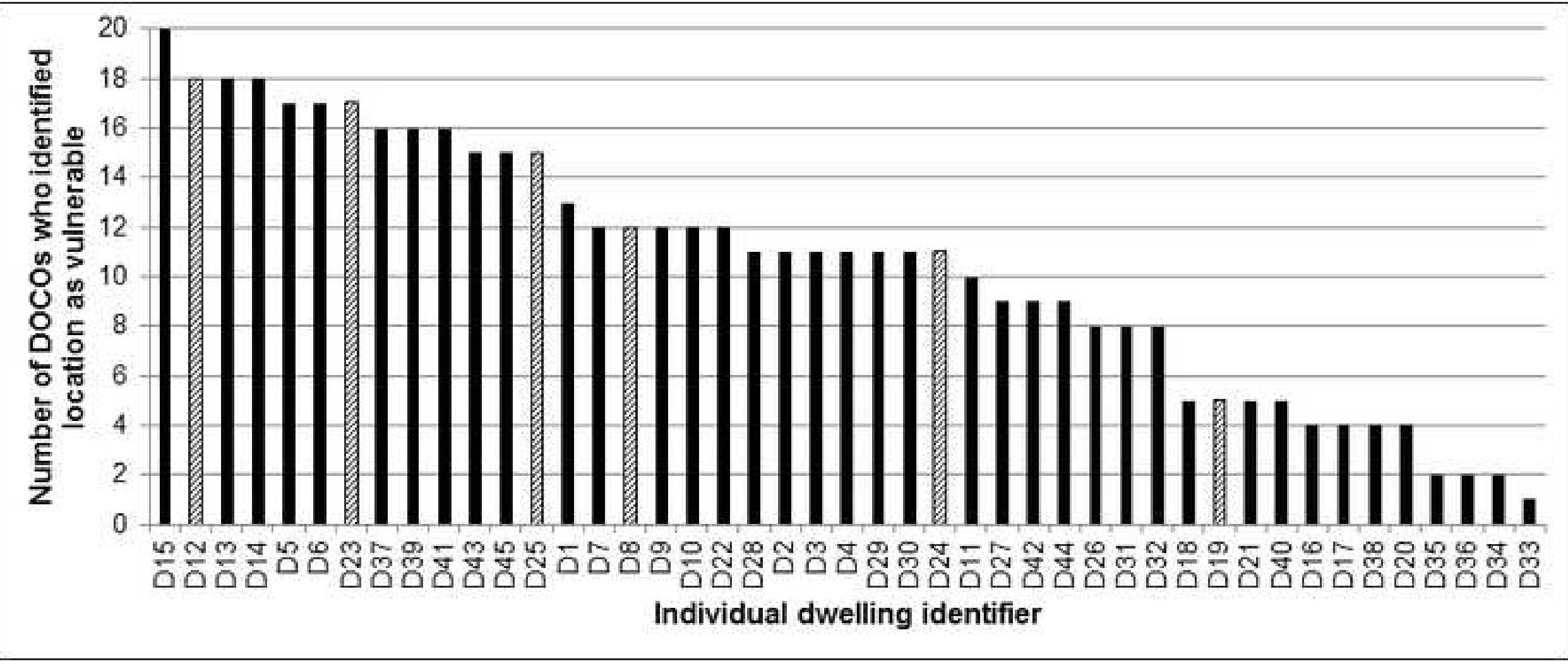


FIGURE 1. Site plan provided to each individual participant

FIGURE 2. Example of annotated site plan

FIGURE 3. Number of locations DOCOs identified as vulnerable to burglary

FIGURE 4. Number of DOCOs identifying individual locations as vulnerable to burglary 
Is it just a guessing game? The application of Crime Prevention through Environmental Design (CPTED) to predict future burglary

Is it just a guessing game? The application of Crime Prevention through Environmental Design (CPTED) to predict future burglary

\author{
Corresponding author: Dr Leanne Monchuk \\ Applied Criminology \& Policing Centre \\ University of Huddersfield \\ Ramsden Building (R2/41), Queensgate, \\ Huddersfield \\ HD1 3DH \\ 1.y.monchuk@hud.ac.uk \\ +44 (0) 1484472670 \\ Co-authors: \\ Professor Ken Pease \\ UCL Jill Dando Institute of Security and Crime Science \\ 35 Tavistock Square, London \\ WC1H 9EZ \\ k.pease@ucl.ac.uk
}

Professor Rachel Armitage

Applied Criminology \& Policing Centre 


\begin{abstract}
Crime Prevention through Environmental Design (CPTED) aims to reduce crime through the design of the built environment. Designing out Crime Officers (DOCOs) are responsible for the delivery of CPTED by assessing planning applications, identifying criminogenic design features and offering remedial advice. Twenty-eight experienced DOCOs from across England and Wales assessed the site plan for one residential development (which had been built a decade earlier) and identified crime risk locations. Predictions of likely locations were compared with four years' police recorded crime data. DOCOs are, to varying extents, able to identify locations which experienced higher levels of crime and disorder. However, they varied widely in the number of locations in which they anticipated burglary would occur.
\end{abstract}

Keywords: Crime Prevention through Environmental Design (CPTED); burglary; built environment; police; residential housing; planning; Designing Out Crime Officers (DOCOs). 


\section{Introduction}

The manipulation of the built environment to reduce the opportunity for crime, disorder and the fear of crime is referred to as Crime Prevention through Environmental Design (CPTED) (Crowe, 2000). CPTED represents a multi-faceted approach to crime reduction. Drawing upon theories from environmental criminology, architecture and urban design, Armitage (2013) defines CPTED as: 'The design, manipulation and management of the built environment to reduce crime and the fear of crime and to enhance sustainability through the process and application of measures at the micro (individual building/structure), meso (neighbourhood) and macro (national) level' (p. 23). CPTED is underpinned by a number of principles (Poyner, 1983; Cozens et al, 2005; Armitage, 2013; Montoya et al, 2016; Armitage \& Monchuk, 2017) with Armitage (2013) suggesting that there are five key principles: physical security; surveillance; movement control; management and maintenance and defensible space.

Physical security aims to ensure that robust security measures (i.e. door and window locks) are installed on individual dwellings to withstand attack from offenders (Tilley et al, 2011; Grove et al, 2012; Brooke, 2013; Tseloni et al, 2017; Armitage, 2017). Surveillance aims to ensure residents are able to observe the areas surrounding their home and their neighbourhood and witness, challenge or report any suspicious 
behaviour (Crowe \& Zahm, 1994; Reynald, 2009; Armitage, 2017; Armitage \& Monchuk, 2017). Movement control aims to ensure that opportunities for access, egress and through movement are minimised to prevent unauthorised access (Nee \& Taylor, 2000; Nee \& Meenaghan, 2006; Johnson \& Bowers, 2010; Armitage et al, 2011; Birks \& Davies, 2017). Management and maintenance relates to the importance of ensuring that a development is free from graffiti, vandalism and litter. In doing so, it transmits signals to residents and visitors that the area is cared for (Cozens, 2008). Defensible space refers to the clearly defined ownership of space in a neighbourhood and encourages and promotes residents to feel a sense of responsibility for the areas adjacent to their home (Newman, 1973; Reynald \& Elffers, 2009; Reynald, 2010). Schneider and Kitchen (2002) state that ensuring residents feel a sense of attachment to space helps to foster a willingness to take control of the area and defend it against intruders.

CPTED depends for its realisation on a number of different agencies, notably the police, urban designers, planning authorities and housing developers. There is no shortage of evidence that the elements of CPTED are relevant to the incidence of crime (see for example Armitage \& Monchuk, 2011), but this is not the focus of the research reported here. Crucially, there is as yet no evidence that those tasked with reviewing planning applications to predict a development's future crime risk have the skill to do so. In short, is there a skill to the application of CPTED? 


\section{The practical application of CPTED}

In medicine, interacting disease processes makes diagnosis challenging, yielding high rates of inaccurate diagnosis and a current movement to algorithm based diagnostic procedures (van Teije, 2017). The anticipation of crime locations is correspondingly challenging. Whilst some criminological research has examined the extent to which practitioners can identify locations of high crime (see Ratcliffe \& McCullagh, 1999, 2001 \& McLaughlin et al, 2007 for example), to the writers' knowledge, no previous research has sought to identify how good crime predictions are, as delivered in advice to planners. Professional expertise develops through the analysis of past performance, so this is a crucial gap in knowledge. A particular problem in the present context is time. Feedback on results comes only years after a development is built. A development needs to be designed, successfully receive planning permission, be built and then fully occupied. A means had to be devised to expedite feedback. The approach reported here should be seen as a viable first step in that process. Its necessary refinements are set out later in the paper. The role of crime prevention advice in planning will briefly be discussed before moving on to the core of the paper, a test of the expertise which lies at the heart of crime prevention advice.

\section{Crime prevention and planning across England}


The importance of embedding CPTED into the design and planning of new developments across England has been documented in a number of key planning policies. Historically, this included Planning Policy Statements One and Three (ODPM, 2005 \& 2010) and guidance documentation such as Safer Places (ODPM, 2004) and World Class Places (DCLG, 2009). However, after a comprehensive review of planning practice guidance (DCLG, 2012a), these publications were disbanded and condensed into a single, standalone document - the National Planning Policy Framework (NPPF) (DCLG, 2012b; Ministry of Housing, Communities and Local Government, 2018). The introduction of the NPPF sought to streamline planning policy and “...provide coherent guidance on urban design principles that should be applied locally" (Paterson, $2012 \mathrm{p}$. 144). Reference to the importance of CPTED in the design of new developments has remained within the NPPF which is crucial as it is this national policy which helps to shape local planning policy. Paragraph 91 of the NPPF states that planning policies and decisions should aim to achieve healthy, inclusive and safe places which:

are safe and accessible, so that crime and disorder, and the fear of crime, do not undermine the quality of life or community cohesion (Ministry of Housing, Communities and Local Government, 2018 p. 25). 
In addition, national Planning Policy Guidance (DCLG, 2012a; DCLG, 2014) further emphasises the role that design can play in the prevention of crime. Guidance states that local authorities should consider the prevention of crime when exercising its planning functions and that applicants should liaise with local police to ensure that crimereduction based planning measures are based upon a clear understanding of the local situation. More recently, the government's Chief Planning Officer wrote to all Chief Planning Officers to remind them of the important role the planning system plays in preventing crime (DCLG, 2017). Whilst this policy and guidance states the importance of including reference to crime prevention at the local planning authority level, it fails to provide any specific instruction as to how this should be implemented in practice (Monchuk, 2016).

\section{Delivery of crime prevention}

In England and Wales, CPTED advice is delivered to planners by Designing out Crime Officers $^{\mathrm{i}}$ (DOCOs). One or more such officers are employed within each of the 43 police forces across England and Wales. They review planning applications and assess the extent to which a development may pose the opportunity for crime and disorder and how they might be mitigated by amendments in the plan. In addition to providing consultation during the pre-planning process, DOCOs can comment after the application has been submitted to the Local Planning Authority (LPA) and can recommend that an 
application be approved, amended or refused. DOCOs seek to engage with urban designers during the concept stage to ensure that the principles of CPTED are incorporated from the outset. This accords with DCLG (2014) guidance which states that crime prevention should not be considered as a stand-alone issue and should be addressed alongside other design considerations. In many cases DOCOs review and comment on planning applications only after they have been submitted to the LPA (Wootton et al, 2009). The earlier a DOCO engages in the design process, the more seamlessly CPTED be can embedded in the design, thereby avoiding later objections by the police based upon crime concerns (Colquhoun, 2004; Schneider \& Kitchen, 2007; Wootton et al, 2009; Monchuk, 2011; Monchuk, in press). Objections raised by the police late in the planning process can be frustrating for applicants. The greater the scale of recommended changes, the more expensive and time-consuming they will be (Monchuk, 2011). DOCOs are also responsible for delivering the Secured by Design (SBD) accreditation scheme. SBD is a UK police initiative which aims to encourage the building industry to design out crime (Secured by Design, 2016). Should a development receive SBD accreditation, this confirms that the development has been built to the principles of CPTED (Armitage \& Monchuk, 2011).

DOCOs are either: i) serving police officers; ii) retired police officers who have returned to force in a civilian support staff role or iii) civilian support staff with no prior 
policing experience (Wootton et al, 2009; Monchuk, 2016). The background of DOCOs employed can differ within and across police forces (Monchuk, 2016). Historically, the role of a DOCO was undertaken by a serving police officer approaching retirement (Weatheritt, 1986). One of the key changes to policing across England and Wales has been the increased employment of lower-paid civilian staff (Newburn, 2003; HMIC, 2004). This allows warranted police officers to concentrate on front-line duties which may require the power of arrest (Garland, 1996). Schneider and Kitchen (2007) warned that the civilianisation of DOCOs could be problematic as they suggest that a DOCO's policing experience adds weight to comments they make on a planning application. However, Minton (2009) argues that the police should not be involved in the design and development process and is concerned that it may result in the over fortification of developments, which may increase levels of fear of crime. Minton (2009), writing specifically about the role of DOCOs in administering the SBD scheme, states:

\footnotetext{
[this] leaves us in the strange position of having police officers, rather than architects, responsible for the way places look and feel, which can create bizarre places (p. 73).
}

All DOCOs are required to complete a two week training course delivered by Police Crime Prevention Initiatives Limited. The course includes modules such as: CPTED; 
the role of DOCOs; interpretation of plans and drawings and planning law and procedures. At the time of writing, Police Crime Prevention Initiatives Limited are seeking to professionalise the training delivered to DOCOs by introducing externally accredited learning and development qualifications. However, a review of the proposed content suggests that it largely remains the same. This is the only dedicated training that DOCOs receive on how to assess plans and drawings, irrespective of their background.

\section{Study rationale}

To date, academic literature has focused upon establishing the effectiveness of developments that have been built to the principles of CPTED and any associated reduction in crime (see for example Armitage, 2000; Teedon et al, 2010; Armitage \& Monchuk, 2011). There is no literature of which the writers' are aware, which tests the skill of DOCOs in identifying locations within a development which anticipate crime risks. A step toward addressing this gap in the literature was important, particularly in response to the publication by the Local Housing Delivery Group (2012) where key stakeholders with an interest in home building raised concerns about the inconsistent application of CPTED by individual DOCOs.

As noted earlier, CPTED design is typically acknowledged by the award which permits the development as a whole to be badged as secure (SBD). However, in many ways the 
plan by plan estimation of relative crime risks within a development is a more rigorous test of DOCO skills. Developments as a whole should meet common standards of security. Potential crime locations within developments should also be identifiable from CPTED principles. Thus, current literature fails to examine how those responsible for designing out crime in England and Wales (DOCOs) assess planning applications; how they go about applying the principles of CPTED and whether they are able to anticipate the locations of future crime risk once the development is built and occupied. Put brutally, the writers' know of no current evidence to suggest that DOCOs can, by reviewing plans, predict where crime is likely to occur within a planned development.

Attempting to establish whether DOCOs are able to predict the locations of crime is, in principle, very simple. One way would be to elicit their predictions of crime from plans for homes that have yet to be built and wait for a considerable amount of time (perhaps a decade) to find out whether they were correct. To shortcut the process, one can provide DOCOs with information about a development which has already been built and occupied, but with which they are unfamiliar. This approach was taken here. DOCOs were shown the site plan for one residential development. They were not told about the force area where it could be found, and none of them worked in the area concerned. They were asked to nominate the parts of the development they believe would prove problematic and experience incidents of crime and disorder, if built as 
planned. The approach was an attempt to simulate (as closely as possible) what their everyday task would be in commenting on proposed developments. The predicted and actual burglary locations would then be compared, to test whether the predicted locations coincided with those which had suffered burglary dwelling and burglary other (e.g. sheds and detached garages) ${ }^{\mathrm{ii}}$.

This paper reports on the following three research questions:

- To what extent do the 28 DOCOs identify different proportions of the development as at risk to burglary? This is important because of the practicalities of the planning process. If a DOCO chooses a large proportion of a development as problematic, it is doubtful whether built environment professionals will value the risk-averse expertise of the DOCO and make any proposed alterations.

- Was there consensus in the locations chosen by DOCOs? Were there locations that all DOCOs deemed problematic? The extremes would be: complete consensus as to whether a location is vulnerable or random selection such that one DOCO's judgement is unpredictable from another DOCO's selection.

- Did the locations chosen by most DOCOs experience burglary post-build? This establishes whether collectively DOCOs can anticipate crime locations better than chance. 


\section{Methodology}

Prior to outlining the methodology used, it may be helpful to cast the study's approach in terms borrowed from psychometrics. A measurement tool's value derives from two attributes, its validity (whether it measures what it purports to measure) and reliability (whether it does so consistently). In this study validity is established by the extent to which the locations predicted to host crime did so, and those which were predicted not to host crime did not do so. This is known as criterion-related validity. Within this study, reliability is tested as the extent to which DOCOs agreed with each other in their predictive judgements. If all DOCOs agreed and were correct in their judgements, it could be concluded that DOCOs judgements were both valid and reliable. The simple analogy with psychometrics breaks down when there are differences amongst DOCOs in the accuracy (validity) of their judgements. The other complication is that the picture is obscured if DOCOs differ in their relative tolerance of false positive and false negative judgements. If some over-predict and others under-predict crime risk, we encounter more complexity in interpretation of practice. Paradoxically, these more complex outcomes are especially valuable in thinking of training using the skills of the most valid judgement makers, and establishment of threshold risk levels common across DOCOs or gradations of risk measurement rather than dichotomous judgements. To anticipate our conclusions, the exercise reported here provides a proof of concept for a 
more nuanced approach to the development and assessment of skills in the anticipation of crime in the yet to be built environment.

Twenty-eight DOCOs that had been in post for the greatest amount of time, from the sample of 129 DOCOs that agreed to take part in the research, were recruited from 18 police forces across England and Wales. A stratified purposive sampling method was employed to include DOCOs who were either: i) serving police officers; ii) retired police officers; iii) police civilian staff with a built environment background or vi) police civilian staff with no policing or built environment background. Participants included: five former built environment professionals; five serving police officers; 10 retired police officers and eight civilian staff. Length in post ranged from five to 20 years. The rationale for selecting the most experienced DOCOs was that it was considered that the more proficient participants were more likely to have experienced successes and mistakes and learnt from problem-solving situations, allowing them to be more reflective in their responses (Paloniemi, 2006).

\section{Selecting the residential case study site}

The site layout plan for a residential development that: i) had been built and was fully occupied and ii) experienced incidents of crime and disorder (as recorded by the local police force) was identified. Hard copy files for all relevant site plans and elevations were sought from the planning authority concerned. The development comprised 41 
individual properties and four blocks of flats, with each block containing 12 individual flats. Thus, in total the development comprised 89 individual dwellings/addresses. The development incorporated 112 car parking spaces and communal cycle storage provision. Built in 2002, the development was fully occupied by the end of 2003 . Burglary data recorded by the local police force during a four-year period (July 2006 July 2010) were requested. The rationale for this time period was twofold. First, owing to a change in the police recording systems, it was not possible to obtain data prior to 2006. Second, to ensure the data could be analysed and the remainder of the exercise designed, developed and administered, data post July 2010 could not be included. During the period of analysis, two burglary dwelling offences and six burglary other offences were recorded at six different locations. The authors' acknowledge that both the four-year period of analysis and the small number of burglaries recorded during this time is a possible limitation. However, to the authors' knowledge this is the first time that such an exercise has been conducted and so the design and implementation of the methodology should be considered both innovative and exploratory.

\section{Conducting the case study exercise}

Twenty-eight DOCOs were recruited as described above and invited to complete the case study exercise. The exercise was completed by the first author on a one-to-one basis. DOCOs were shown the site plan for the development (Figure 1) and provided 
with generic information relating to the development (number of dwellings and car parking spaces). DOCOs are typically provided with this descriptive information when reviewing planning applications. DOCOs were asked to spend a couple of minutes reviewing and digesting the information provided and asked the two following generic questions:

- From looking at the site plan, what initially do you like about the plan from a crime prevention perspective and why? and

- What don't you like about the plan and why?

DOCOs were asked to think aloud to help understand: how they assessed the plan (e.g. as per the principles of CPTED or by working through the plan in a certain direction); how they went about assessing future crime risk and the comments they would make to the planning officer/applicant regarding the proposed design and layout. DOCOs were encouraged to annotate the site plan to mark the locations that they perceived to be vulnerable to crime and disorder. For each annotation, participants were asked to provide a justification as to why they had identified that area as vulnerable and to detail they would predict to occur at each location. After this general assessment, DOCOs were then asked to annotate the site plan to mark the locations that, in their professional opinion, were specifically at risk from burglary dwelling and burglary in a building other than a dwelling. DOCOs were told that two burglary dwelling offences and six 
burglary other offences were recorded by the police between July 2006 and July 2010. This is the only information they were told. They were not told at how many locations these offences occurred, nor the specific locations of these offences. Thus, the data available for analysis comprises: a site plan for each of the 28 DOCOs annotated with the locations at which they predict burglary occurred (Figure 2) and the addresses of the dwellings that experienced burglary between July 2006 and July 2010 which were recorded by the police.

FIGURE 1. Site plan provided to each individual participant

\section{[Insert Figure 1 here]}

FIGURE 2. Example of annotated site plan

\section{[Insert Figure 2 here]}

Prior to presenting the key findings from this exercise, it is important to note the following. Although there were a total of 48 individual flats, each block rather than each individual flat was considered as the unit of analysis. This was to compensate for the fact that in some instances police recorded crime data relating to blocks of flats or apartments can lack detail (Armitage et al, 2011). Also, in the current study the plans provided did not distinguish individual flats, so there was no alternative to treating the 
block of flats as a single address. Thus, the total number of properties included in the analysis was 45 (41 individual properties and four blocks of flats).

\section{Results}

As noted earlier, during the period of analysis, two burglary dwelling offences and six burglary other offences had been recorded at six different locations. The number of locations identified as crime prone by the 28 DOCOs varied from three to 31 (mean 16.9, standard deviation 8.9). Figure 3 shows the distribution of numbers of locations identified as vulnerable by the participants. The suggestion from the data is that some DOCOs are risk averse in identifying many more homes as being burglary-prone than were victimised. Possible reasons for this are supplied in the discussion section of this paper.

FIGURE 3. Number of locations DOCOs identified as vulnerable to burglary

\section{[Insert Figure 3 here]}

Figure 4 shows the 45 locations within the development alongside the number of DOCOs who identified each location as vulnerable to burglary. The bars in black represent locations that were not victimised and those in with a dashed line denote a victimised location. It is interesting to note that no location was deemed vulnerable by all 28 participants, but that each of the 45 locations was identified as being vulnerable to 
burglary by at least one DOCO. Each of the six burgled locations were judged vulnerable by at least 5 DOCOs with 18 DOCOs (64\%) correctly identifying location D12 and 17 (61\%) identifying location D23. 15 DOCOs (54\%) identified location D25; $12(43 \%)$ identified location D8; 11 (39\%) identified D24 and $5(18 \%)$ identified 
FIGURE 4. Number of DOCOs identifying individual locations as vulnerable to burglary

\section{[Insert Figure 4 here]}


location D19. What these data suggest is that DOCOs lack consensus in their assessment of risk of burglary. The implications of the variation identified above may be attributed to one of two reasons. First, if those locations were consistently identified as vulnerable by most DOCOs, the conclusion would be that they were making judgements true to CPTED, but CPTED is (necessarily) an imperfect predictor of burglary. If however, the CPTED obvious locations were not identified as vulnerable by most or all DOCOs, the DOCOs were using non-CPTED criteria of vulnerability. Analysis of the physical characteristics of each of the 45 locations suggests that to a substantial extent, the latter account prevails.

\section{Did the locations chosen by most DOCOs experience burglary post-build?}

Whilst the data presented in Figure 4 show the locations which DOCOs deemed to be most vulnerable to burglary, it is important to identify whether DOCOs in the aggregate can predict the location of burglary. Put simply, were DOCOs in the aggregate better than chance in identifying burglary risks? Table 1 presents the relevant data and shows that in total 1,260 predictions (28 DOCOs x 45 locations) were made. Looked at another way, Table 1 shows that a total of 472 predictions were made identifying locations as vulnerable, with $78(17 \%)$ of these being correct - the location was identified as vulnerable and did experience burglary during the period of analysis. The remainder of predictions ( $\mathrm{n}=394$ or 83\%) identified locations which were deemed vulnerable but did not experience any incidents of burglary during the period of analysis.

TABLE 1. Contingency table of recorded burglary and identification as vulnerable

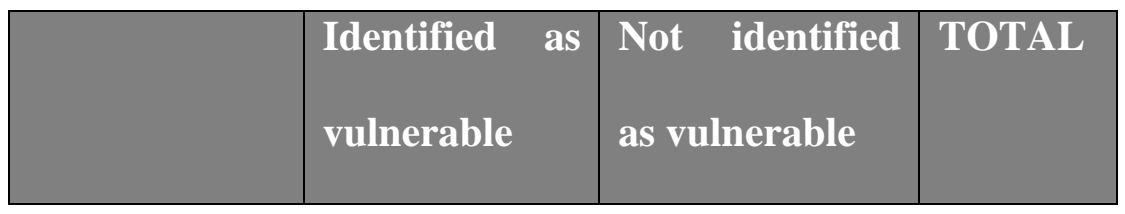


DOCOs were able to identify the locations of the victimised and non-victimised locations rather better than chance. A chi-square test was performed to examine the relationship between the predictions made by the DOCOs. The relationship between these variables (vulnerability and victimisation) was significant, $X^{2}(1 \mathrm{df}, N=1260)=6.65, p<0.05$. DOCOs were better than chance in identifying the burgled homes. However it is acknowledged that the data breaches the requirement of independence of observations and it is presented only as suggestive.

\section{Discussion}

This is, as far as the writers' know, the first study of an important topic and its limitations are acknowledged. The first potential concern is the impression which it gives of the limited and varied skill of DOCOs and such an impression is not justified. If CPTED is relevant to crime reduction, anticipation of crime on the basis of design attributes of developments should be better than chance. However how much better than chance it could be is not, and perhaps cannot ethically be determined. Characteristics of occupants, crime in contiguous areas, and prevailing rates of crime are other factors relevant to anticipated crime risk.

Self-evidently, the study design meant that DOCOs could not physically visit the site and the surrounding area which is something that they may ordinarily do when assessing planning applications. The site was no longer a site! Further, the DOCOs were not able to discuss the specific aspects of the application with other key stakeholders (such as planning officers, 
Highways, policing colleagues). During a number of the interviews, DOCOs enquired whether the development was located within an urban or a rural area and to ensure consistency across the sample, this information was not provided to the participant. Thus, the exercise did not provide the DOCOs with all the information required when undertaking their assessment and that would ordinarily be available to them.

However, as all DOCOs in the work reported here were able to access the same information to inform their assessment, the authors' are convinced that this was the best approach to adopt. Whilst the findings overall are positive, these findings represent the worst case scenario. Should the participants have been able to access additional data (such as police intelligence) their assessment of what locations were vulnerable to burglary, perhaps may have been more accurate. Finally, the findings are based upon police recorded crime data over a four year period. Thus, it might be the case that locations which have been identified by the DOCOs as being vulnerable do actually experience burglary in the future. However, this still would not address the disparity in which the DOCOs identified each of the 45 locations as vulnerable.

The research is about improvement, not criticism. It has, uniquely as far as the writers' are aware, focused upon those responsible for its application and delivery. It has demonstrated that when presented with a residential plan, DOCOs are able to, to a varying extent, identify locations which have experienced burglary. However, this skill varies with some DOCOs identifying only a small proportion of the development as at risk, with others adopting a much more risk averse stance deeming a large proportion of the development at risk. This variation raises concerns about the inconsistency with which CPTED is implemented on the ground and reiterates the concerns raised by the Local Housing Development Group (2012). One could argue that this inconsistency is because in reality DOCOs are located across the 
country and therefore regularly assess developments located in different areas, each with different crime risks and levels of crime. Thus, unknowingly, it is possible that the DOCOs assessed the development as if it was located within their own force area. Nonetheless, the rationale behind providing the 28 most experienced DOCOs with the same residential development and with the same generic information (i.e. the number of individual dwellings) was to elicit the extent of this variation. Further, it became clear that at least some of the judgements were not made with the principles of CPTED in mind, in that locations which were clearly vulnerable on the basis of CPTED principles were not identified as such by many DOCOs. However, DOCOs are the sole tasked gatekeepers of inbuilt home security, thus it is important that they are consulted and engaged as early in the design process as possible to work in collaboration with urban designers to incorporate crime prevention measures seamlessly into the design.

It could be argued that it is more important to ensure that DOCOs adopt an over cautious approach and select all the potentially victimised sites, no matter how much of the site they deem vulnerable. However, if the application of CPTED is merely about adopting a riskaverse, over-cautious approach to the design of new residential developments, one must then ask the following key questions. First, why does the plan need to be reviewed by a professional whose job it is to accurately predict future risk in the design of new developments? One could assume risk across entire developments and this would not require the skill of a professional. Second, if dedicated roles exist to try and predict risk, one needs to examine what makes these professionals skilled in assessing risk commensurate with predicted future risk. What qualities, experience and training have they undergone allowing them to perform this role adequately and what continuing training and professional development do they require to remain abreast of planning updates and criminological 
research? There is no skill in someone assessing an entire development as risky, and it is highly likely that there will be a conflict with other key policies and agendas which are of equal importance to key stakeholders (Local Housing Development Group, 2012). However, there is skill in being able to draw upon knowledge and intelligence and undertake a comprehensive assessment to help make specific and targeted recommendations which are commensurate with the presenting risk. In short, the key skill is in differential risk assessment. The approach adopted by some of the DOCOs and the over-prediction of burglary risk demonstrates a lack of confidence in their predictive skill. For example, one DOCO identified thirty-one locations (69\% of the total development) as vulnerable. This over cautious approach potentially relates to a fear about any repercussions should they have not predicted potential crime and disorder issues. In short, they may over-predict because they fear failure. This research has confirmed that there is a skill to applying CPTED at the planning stage. However, it also confirms that there is scope for the skill to be improved and the authors' strongly argue that the role of DOCOs must be afforded more attention in terms of training and continued professional development.

The writers' believe that elaboration of the research design adopted here has both immediate usefulness as a training approach and is capable of refinement as a research tool. First, let us rehearse its usefulness as a training tool. Its advantage over any alternative is that it can short circuit the lengthy delays in feedback of results as to the crime rate of new developments. By rating plans of developments which have in fact been built in the past and whose crime experience is now evident, DOCO judgements may be tested more or less immediately. The writers' envisage the incorporation of the approach as an essential part of DOCO training, in which officers make individual judgements of plans, which are then compared, against each 
other and against CPTED principles. This would be tested by a movement towards consensus and may well yield supplementary ideas to CPTED orthodoxy.

As for research refinement, the writers' envisage providing the same plan but with different supplementary information, for example about the crime history of contiguous areas. They also envisage the use of older plans to gain crime data over the longer term to see whether DOCO recommendations become more or less salient to crime outcomes over the short or longer term. The approach could also readily be extended to other crime types.

\section{References}

Armitage, R. (2000) An Evaluation of Secured by Design Housing within West Yorkshire Briefing Note 7/00. London: Home Office.

Armitage, R. (2013) Crime Prevention through Housing Design: Policy and Practice, (Basingstoke: Palgrave Macmillan).

Armitage, R. (2017) Burglars' Take on Crime Prevention through Environmental Design, Security Journal. 31(1), pp. 285-304.

Armitage, R. \& Monchuk, L. (2011) Sustaining the crime reduction impact of designing out crime: Re-evaluating the Secured by Design scheme 10 years on, Security Journal, 24(4), pp. 320-343. 
Armitage, R. \& Monchuk, L. (2017) What Is CPTED? Reconnecting Theory with Application in the Words of Users and Abusers, Policing: A Journal of Policy and Practice. DOI: $10.1093 /$ police/pax004.

Armitage, R., Monchuk, L. \& Rogerson, M. (2011) It looks good, but what is it like to live there? Exploring the impact of innovative housing design on crime, European Journal on Criminal Policy and Research, 17(1), pp. 29-54.

Birks, D. \& Davies, T. (2017) Street Network Structure and Crime Risk: An Agent-Based Investigation of the Encounter and Enclosure Hypotheses, Criminology, 55(4), pp. 900-937.

Brooke, M. (2013) Secured by Design - The Story So Far, Safer Communities, 12(4), pp. 154-162.

Colquhoun, I. (2004) Design out crime: creating safe and sustainable communities, Crime Prevention and Community Safety: An International Journal, 6(4), pp. 57-70.

Cozens, P. (2008) Crime prevention through environmental design, in: R. Wortley \& L. Mazerolle (Eds) Environmental Criminology and Crime Analysis, pp. 153-194 (Cullompton: Willan Publishing).

Cozens, P. Saville, G. \& Hillier, D. (2005) Crime prevention through environmental design (CPTED): a review and modern bibliography, Property Management, 23(5), pp. 328-356. 
Crowe, T. (2000) Crime Prevention through Environmental Design: Applications of Architectural Design and Space Management Concepts, $2^{\text {nd }}$ ed. (Boston, MA: ButterworthHeinemann).

Crowe, T. \& Zahm, D. (1994) Crime Prevention through Environmental Design. Washington: National Association of Home Builders.

DCLG (2009) World Class Places: The Government's strategy for improving quality of place. London: DCLG.

DCLG (2012a) External Review of Government Planning Practice Guidance. London: DCLG.

DCLG (2012b) National Planning Policy Framework. London: DCLG.

DCLG (2014) Guidance: Design. Available at: https://www.gov.uk/guidance/design\#crimeprevention (accessed 21 July 2017).

DCLG (2017) Letter to Chief Planning Officer. Available at: https://www.gov.uk/government/uploads/system/uploads/attachment_data/file/627395/Chief_ Planner_letter_-_security_and_planning.pdf (accessed 20 th July 2017).

Garland, D. (1996) The limits of the sovereign state: Strategies of crime control in contemporary society, British Journal of Criminology, 3(4), pp. 445-471. 
Grove, L., Tseloni, A. \& Tilley, N. (2012) Crime, Inequality and Change in England and Wales, in: J. van Dijk, A. Tseloni \& G, Farrell (Eds) The International Crime Drop. New Directions in Research, pp. 182-199 (Baisingstoke: Palgrave Macmillan).

HMIC (2004) Modernising the police service: A thematic inspection of workforce modernisation - the role, management and deployment of police staff in the police service in England and Wales. London: HMIC.

Johnson, S., \& Bowers, K. (2010) Permeability and Burglary Risk: Are Cul-de-Sacs Safer?, Quantitative Journal of Criminology, 26(1), pp. 89-111.

Local Housing Delivery Group (2012) A review of local standards for the delivery of new homes. London: Local Housing Delivery Group.

McLaughlin, L. M., Johnson, S. D., Bowers, K. J., Birks, D. J., \& Pease, K. (2007) Police perceptions of the long-and short-term spatial distribution of residential burglary, International Journal of Police Science \& Management, 9(2), pp. 99-111.

Ministry of Housing, Communities and Local Government (2018) National Planning Policy Framework. London: Ministry of Housing, Communities and Local Government.

Minton, A. (2009) Ground Control: Fear and happiness in the twenty-first-century city, (London: Penguin Books). 
Monchuk, L. (2011) The Way Forward in Designing Out Crime?: Greater Manchester Police Design for Security Consultancy, Safer Communities: a journal of practice, opinion, policy and research, 10(3), pp. 31-40.

Monchuk, L. (2016) Crime Prevention through Environmental Design (CPTED): Investigating Its Application and Delivery in England and Wales. Doctoral Thesis, University of Huddersfield, 2016.

Monchuk, L. (in press) A Decade Developing the Delivery of CPTED across Greater Manchester, in: R. Armitage \& P. Ekblom (eds) Rebuilding Crime Prevention Through Environmental Design: Strengthening the links with Crime Science (Abingdon: Routledge).

Montoya, L., Junger, M. \& Ongena, Y. (2016) The Relation Between Residential Property and its Surroundings and Day- and Night-Time Residential Burglary, Environment and Behavior, 48(4), pp. 515-549.

Nee, C. \& Meenaghan, A. (2006) Expert decision making in burglars, British Journal of Criminology, 46(5), pp. 935-949.

Nee, C. \& Taylor, M. (2000) Examining burglars' target selection: Interview, experiment or ethnomethodology? Psychology, Crime \& Law 6(1), pp. 45-59.

Newburn, T. (2003) Handbook of Policing, $2^{\text {nd }}$ ed. (Cullompton: Willan Publishing). 
Newman, O. (1973) Defensible Space: People and Design in the Violent City, (London, Architectural Press).

ODPM (2004) Safer Places - The Planning System and Crime Prevention. London: HMSO.

ODPM (2005) Planning Policy Statement 1: Delivering Sustainable Development. London: HMSO.

ODPM (2010) Planning Policy Statement 3: Housing. $2^{\text {nd }}$ ed. London: HMSO.

Paloniemi, S. (2006) Experience, competence and workplace learning, Journal of Workplace Learning, 18(7), pp. $439-450$.

Paterson, E. (2012) Urban design and the national planning policy framework for England, URBAN DESIGN International, 17(2), pp. 144-155.

Poyner, B. (1983) Design against crime: Beyond defensible space, (London: Butterworth).

Ratcliffe, J. H., \& McCullagh, M. J. (1999) Hotbeds of crime and the search for spatial accuracy, Journal of Geographical Systems, 1(4), pp. 385-398.

Ratcliffe, J. H., \& McCullagh, M. J. (2001) Chasing ghosts? Police perception of high crime areas, British Journal of Criminology, 41(2), pp. 330-341.

Reynald, D. (2009) Guardianship in action: Developing a new tool for measurement, Crime Prevention and Community Safety: An international journal, 11(1), pp. 1-20. 
Reynald, D. (2010) Guardians on guardianship: Factors affecting the willingness to supervise, the ability to detect potential offenders, and the willingness to intervene, Journal of Research in Crime and Delinquency, 47 (3), pp. 358-390.

Reynald, D.M., \& Elffers, H. (2009) The Future of Newman's Defensible Space Theory Linking Defensible Space and the Routine Activities of Place, European Journal of Criminology 6(1), pp. 25-46.

Schneider, R. \& Kitchen, T. (2002) Planning for Crime Prevention, (London: Routledge).

Schneider, R. \& Kitchen, T. (2007) Crime Prevention and the Built Environment, (London: Routledge).

Secured by Design (2016) Secured by Design New Homes 2016: Version 1. London: Secured by Design.

Teedon, P., Reid, T., Griffiths, P. \& McFadyen, A. (2010) Evaluating Secured by Design door and window installations: Effects on residential crime, Crime Prevention and Community Safety: An International Journal, 12(4), pp. 246-262.

Tilley, N., Tseloni, A. \& Farrell, G. (2011) Income disparities of burglary risk. Security availability during the crime drop, British Journal of Criminology, 51(2), pp. 296 - 313.

Tseloni, A., Thompson, R., Grove, L., Tilley, N. \& Farrell, G. (2017) The effectiveness of burglary security devices, Security Journal, 30(2), pp. 646-664. 
Van Tieje, A. (2017) Artificial Intelligence in Medicine, (New York: Springer).

Weatheritt, M. (1986) Innovations in Policing, (London: Croom Helm).

Wootton, A., Davey, C., Marselle, M., Armitage, R. \& Monchuk, L. (2009) NPCPS Implementation Planning Project. Salford: Design Against Crime Solution Centre, University of Salford.

\footnotetext{
Notes

i Previously referred to as: Architectural Liaison Officers (ALOs) or Crime Prevention Design Advisors (CPDAs).

ii As of April 2017, burglary dwelling and burglary other was reclassified as 'residential burglary' (ONS, 2017).
} 